\title{
Role of Decompression in Late Presentation of Cervical Spinal Cord Disorders
}

\author{
Sandeep Shrivastava, Harshal Sakale, Rajesh Dulani, Pradeep K Singh, Manoj Sanrakhia \\ Department of Orthopaedics, Jawaharlal Nehru Medical College, Datta Meghe Institute of Medical Sciences, Wardha, India
}

\begin{abstract}
Study Design: Prospective study conducted at Jawaharlal Nehru Medical College, Datta Meghe Institute of Medical Sciences, Wardha, India.

Purpose: To show the efficacy of decompression in the late presentation of cervical spinal cord disorders.

Overview of Literature: Studies by various authors have shown that early spinal decompression results in better neurological outcomes.

Methods: From January 2003 to January 2005, 11 of the 41 patients with cervical spinal cord compression, meeting the inclusion criteria, underwent anterior decompression; interbody graft placement and stabilization by anterior cervical locking plate. The neurologic and functional outcomes were recorded.

Results: Five patients had spinal cord injury and 6 patients had compressive cervical myelopathy. Complications included 1 death and 1 plate loosening. No patient lost their preoperative neurological status. One patient had no improvement, 2 patients showed full recovery. The mean follow-up is 28.3 month. At the of rehabilitation, 6 were able to walk without support), 2 could walk with support, and 1 needed a wheelchair. The average American Spinal Injury Association motor score on admission to the hospital, 32.8 (standard deviation [SD], 30.5); admission to rehabilitation, 38.6 (SD, 32.4); discharge from rehabilitation, 46.2 (SD, 33.7). The most recent follow-up was 64.0 (SD, 35.3).

Conclusions: The anterior approach for cervical decompression allows for adequate decompression. This decompression is the best chance offered in even late reported cases, including posttraumatic cases where there is no evidence of cord transactions. The use of anterior cervical plates reduces the chances of graft loosening, extruding, or collapsing.
\end{abstract}

Keywords: Cervical vertebrae; Neglected disease; Quadriparesis; Surgical decompression

\section{Introduction}

Quadriparesis caused by degenerative, mechanical or traumatic injury to the spinal cord is a devastating event on a personal and family level as well as a tremendous financial burden to society because of its attendant morbidity, the expensive and prolonged necessary treatment regime, and the patient's life-long dependence on medical ancillary staff and resources [1]. Cervical spinal injury occurs most frequently in the young male patient at an average age of 35 years. The most frequent etiologies of injury are motor vehicle accidents and falls, followed by violence and sports-related injuries. Approximately 40\% of cervical spinal cord injury patients present with complete spinal cord injuries, $40 \%$ with incomplete injury, and $20 \%$ with either no cord or only root lesions [2]. De-

Received Jan 9, 2013; Revised Mar 6, 2013; Accepted Mar 13, 2013

Corresponding author: Sandeep Shrivastava

Department of Orthopaedics, Jawaharlal Nehru Medical College, Datta Meghe Institute of Medical Sciences,

Sawangi, Wardha, India

Tel: +91-9765404068, Fax: +91-7152-287714, E-mail: drsandeepshrivastava@hotmail.com 
generative spinal cord injury or myelopathy causes slow spinal cord damage and is usually incomplete in neurological status and affects the older generation.

A great deal of discussion has occurred as to which treatment course is most helpful in ensuring maximum neurologic improvement after a cervical spinal cord injury [2-5]. All these studies show that an early decompression of the spinal cord is crucial in the prognosis of neurological recovery; however, no report has been presented on the advantages of late decompression of the spinal cord in cases that are presented late due to unavoidable circumstances.

In developing countries such as India, especially in rural situations, patients suffering from quadriparisis are usually reported very late with advance symptoms. There are many factors in the rural set-up of India which force them to present late to a doctor. These factors can range from lack of awareness both in the patient as well as in the medical fraternity available in the rural areas, blind faith in the non-traditional methods of treatment, lack of transport, non-availability of modern equipment and facilities (magnetic resonance imaging [MRI], computed tomography $[\mathrm{CT}]$ scan) in all the centers and inability to afford modern medical treatment due to monetary restrictions. Mostly, these patients are left to their fate for natural outcomes.

We undertook a case-series study to evaluate the role of decompression and stabilization of cervical spine through the anterior approach. The purpose of this study was to determine the improved neurologic outcome in patients of cervical spinal cord compression present late due to unavoidable circumstances. A subsequent report will discuss the morbidity and cost to provide basic surgical intervention to these patients.

\section{Materials and Methods}

This is a prospective study conducted at Jawaharlal Nehru Medical College, Datta Meghe Institute of Medical Sciences, Wardha, a tertiary care centre in rural India. An analysis is presented of evaluating the neurologic outcome after anterior decompressive surgery in late neglected cases of mechanical cervical spinal cord disorder (level III evidence). No benefits have been received from any party.

Of the total 41 patients with cervical spinal cord compression admitted between January 2003 and January
2005, 11 patients met the inclusion criteria and gave their consent for the study. These patients were then subjected to decompression and stabilization and were followed up to observe the outcome.

The following are criteria for the inclusion: 1) Patients with an American Spinal Injury Association (ASIA) impairment scale of A-D, neurologic level of C3-T1, a minimum age of 15 years, and maximum age of 75 years; 2) Patients admitted 3 months after spinal cord injury and who consented for surgical intervention; 3) Cervical spinal cord compression either due to an acute traumatic event or chronic degenerative process with radiographically documented cord compression due to cord encroachment by anterior vertebral body elements, disc material, or posterior vertebral elements as a result of fracture subluxation or dislocation; and 4) Patients or relatives who were able to read and understand the nature of the study and give informed consent.

The following are criteria for the exclusion: 1) There could be no other major associated surgical or orthopedic injury that could interfere with the neurologic examination; 2) There could be no cervical spinal cord abnormalities due to other neurological disease processes (e.g., multiple sclerosis, stroke); 3) There could be no concurrent illness that would interfere with surgery; and 4) Patients with worsening general condition due to complications from long standing immobilization such as chronic bone deep grossly infected pressure sores, severe pneumonia or urinary tract infection were excluded.

All patients underwent preoperative magnetic resonance imaging. Patients in the group were scheduled for surgery at an elective time period according to their coexisting medical issues. Patients with trauma who participated in this study did not undergo a traction reduction before their surgical procedure. None of the patients were treated with steroids. Surgical intervention consisted of relieving pressure on the spinal cord through an anterior decompressive and stabilizing procedure or a stabilization procedure alone. Data collected were analyzed for age, gender, number of days before surgery in the acute hospital setting, number of postoperative days in the acute hospital setting, number of days in rehabilitation, number of days to most recent follow-up, motor score on admission to the acute hospital, motor score on admission to rehabilitation, motor score on discharge from rehabilitation, and motor score at most recent follow-up. Motor and sensory examinations were performed at ad- 
Table 1. Preoperartive details

\begin{tabular}{|c|c|c|c|c|c|c|c|}
\hline $\begin{array}{c}\text { Serial no./ } \\
\text { patient } \\
\text { name) }\end{array}$ & $\begin{array}{l}\text { Age }(y r) / \\
\text { sex }\end{array}$ & $\begin{array}{l}\text { Duration } \\
\text { (mo) }\end{array}$ & Cause & Level & $\begin{array}{l}\text { Clinical profile: } \\
\text { quadriparesis } \\
\text { (MRSC) }\end{array}$ & $\begin{array}{l}\text { Associated } \\
\text { injury/illness }\end{array}$ & Investigation \\
\hline $1 / S D$ & $55 / \mathrm{M}$ & 6 & Posttraumatic & C5-6 & Gr 1-2 & Head injury, bed sore & Contrast MRI \\
\hline $2 / \mathrm{KM}$ & $67 / \mathrm{M}$ & 5 & Chr. PIVD & C4-5-6 & Gr 1 & - & Contrast MRI \\
\hline 3/AJ & $58 / \mathrm{M}$ & 12 & Chr. PIVD & C5-6 & Gr 2-3 & Diabetes medicine & Contrast MRI \\
\hline 4/SK & $32 / \mathrm{M}$ & 10 & Chr. PIVD & C5-6 & Gr 1 & $\begin{array}{l}\text { Flexion contracture of } \\
\text { lower extremity }\end{array}$ & Contrast MRI \\
\hline $5 / \mathrm{VB}$ & $28 / \mathrm{M}$ & 18 & Posttraumatic & C4-5-6 & Gr 1 & $\begin{array}{l}\text { Fracture of clavicle, } \\
\text { contracture of extremities }\end{array}$ & Contrast MRI \\
\hline $6 / S B$ & $34 / F$ & 10 & Posttraumatic & C5-6 & Gr 1-2 & Head injury, bed sore & CT scan-contrast \\
\hline 7/CT & $38 / \mathrm{M}$ & 3 & Posttraumatic & C5-6 & Gr 1-2 & $\begin{array}{l}\text { Frcature of pelvis, } \\
\text { bed sore present }\end{array}$ & Contrast MRI \\
\hline 8/MS & $48 / \mathrm{M}$ & 10 & Chr. PIVD & C4-5 & Gr 2-3 & - & Contrast MRI \\
\hline 9/AM & $42 / \mathrm{M}$ & 6 & Chr. PIVD & C3-4-5-6 & Gr 2-3 & - & Contrast MRI \\
\hline $10 / K B$ & $35 / F$ & 5 & Posttraumatic & C4-5 & Gr 1 & - & Contrast MRI \\
\hline 11/UM & $63 / \mathrm{M}$ & 8 & Chr. PIVD & C6-7 & Gr 1-2 & Hypertension & Contrast MRI \\
\hline
\end{tabular}

MRSC, motor score; Gr, grade; MRI, magnetic resonance imaging; Chr., chronic; PIVD, prolapsed inter vertebral disc; CT, computed tomography.

Table 2. Operative details

\begin{tabular}{|c|c|c|c|c|c|c|}
\hline $\begin{array}{c}\text { Serial } \\
\text { no. }\end{array}$ & Decompression & Graft/fusion & Stabilization & $\begin{array}{l}\text { Duration } \\
\text { (hr) }\end{array}$ & Additional surgery & $\begin{array}{l}\text { Difficulties/ } \\
\text { complication }\end{array}$ \\
\hline 1 & Discectomy & $\begin{array}{c}\text { Tricortical illiac } \\
\text { graft/1 level }\end{array}$ & $\begin{array}{l}\text { Anterior cervical } \\
\text { locking plate }\end{array}$ & 2.30 & - & Plate positioning \\
\hline 2 & Corpectomy C5 & Do/2 levels & Do & 2.45 & - & - \\
\hline 3 & Discectomy & Do/1 level & Do & 2 & - & Bleeding \\
\hline 4 & Discectomy & Do/1 level & Do & 1.45 & Percutaneous contracture release & - \\
\hline 5 & Corpectomy C5 & Do/2 level & Do & 2.30 & $\begin{array}{l}\text { Contracture release and } \\
\text { miscellaneous sliding of bilateral } \\
\text { elbow and It thumb }\end{array}$ & - \\
\hline 6 & Discectomy & Do/1 level & Do & 1.30 & - & - \\
\hline 7 & Discectmoy & Do/1 level & Do & 2 & - & - \\
\hline 8 & Discectomy & Do/1 level & Do & 2.30 & - & Bleeding \\
\hline 9 & Discectomy & Do/3 level & Do & 4 & - & $\begin{array}{l}\text { Superior thyroid vessel, } \\
\text { extension of incision } \\
\text { and screw placement- } \\
\text { plate sizing }\end{array}$ \\
\hline 10 & Disectomy & Do/1 level & Do & 2 & - & - \\
\hline 11 & Diecsctomy & Do/1 level & Do & 1.30 & - & - \\
\hline
\end{tabular}

mission to the acute hospital, at 72 hours postadmission, immediately after surgery, on admission to rehabilitation, on discharge from rehabilitation, and at the most recent follow-up. A standardized neurologic examination form was used in our study, which was adapted from the ASIA score. The information collected included manual muscle test scores of all key muscles, sensory examination of pin prick and touch, sacral and deep tendon reflexes, and 
muscle tone evaluation. The Frankel grade, motor scores, and neurologic level were also noted. The motor scores were analyzed using the Mann-Whitney $U$ test. Mechanisms of injury, preoperative (Table 1) and operative (Table 2), were also recorded.

\section{Results}

The group consisted of 11 patients (9 men and 2 women) with an average age of 45.5 years (range, 28 to 67 years). Five of the patients were posttraumatic and 6 showed compressive spondylolytic myelopathy because of chronic prolapse intervertebral disc. All were quadriplegics of less than grade 3 (nonuseful), 7 patients had parasthesia and sensory losses corresponding to their level of pathology, and 4 had complete loss of sensation below the nipple level. All had a certain degree of bowel and bladder problems. Three had bedsores and two patients had additional flexion contractures of the extremities.

Patients spent an average of 5.5 days before surgery in the acute hospital setting. In 7 patients the single level fusion was performed, in 3 patients double level fusion was performed, and in 1 patient 3 level fusion was performed. All patients underwent contrast MRI of the cervical spine, except one who underwent contrast CT scan.

All the operations were performed under C-arm IITV, under general anesthesia. Anterior approach from the left side was used in all cases, after identification of the levels by needle placement. The commonest level was 5 of C5-6; 2 each of C4-5 and C4-5-6; 1 of C6-7 and 1 of C3-4-5-6 patients. Corpectomy was performed in two patients, 1 patient underwent multilevel discectomy, while the remaining patients ,all underwent single level discectomy. Spinal cord monitoring was not possible intraoperatively because of the lack of equipment.

All patients underwent grafts harvested from the iliac crest and tricortical with and anterior slope. All were stabilized with anterior cervical titanium locking plates.

The mean duration of surgery was 2.11 hours, with a minimum of 1.30 hours and a maximum of 4 hours for a 3 level fusion. One patient in the group died during the acute postoperative period. Patients who had not undergone stabilization with plates were already excluded from this study. The mean follow up is 25.72 months with the longest being 34 months and the shortest being 24 months.

All patients with single level fusion were given soft cervical collars for 3 weeks, primarily as a confidence building measure to mobilize the patient early. Patients with two level fusion were given hard cervical collars for 4 weeks. Three patients needed further surgeries for bedsores, and two had contracture release of extremities. All were mobilized out of bed on a wheelchair by the second postoperative day. One patient died on the 7th day due to pneumonia leading to septic multiorgan failure. All ten patients achieved adequate interbody fusion and graft failures such as collapse, retropulsion, extrusion, or loosening were not observed. In 1 patient, there was a late partial loosening of screws.

Of the remaining 10 patients, 6 are independent walkers, walking without support; 3 use walking aids such as a walker or stick; one has not shown any improvement and remains in a wheelchair. In seven patients bowel and bladder symptoms had subsided and the other 3 patients were trained in self catheterization. There were no infections of the surgical site and no reoperation.

None of the patients deteriorated further neurologically. Only one patient complained of a feeling of stiffness of the neck; underwent double level fusion. Clinically there was no remarkable neck movement restriction.

Their average motor score on admission to the hospital was 32.8 (standard deviation [SD], 30.5). Their average motor score on admission to rehabilitation was 38.6 (SD, $32.4)$ and their motor score on discharge from rehabilitation was 46.2 (SD, 33.7). Their average motor score at the most recent follow-up was 64.0 (SD, 35.3). Patients in this group spent an average of 17.7 days after surgery in the acute hospital setting and 51.1 days in rehabilitation. Their average time to follow-up was 28.3 weeks (Table 3).

\section{Discussion}

In our country, especially in rural areas, patients do not usually report their condition early. The golden standard of decompressing within 6 to 72 hours is usually not feasible for a variety of reasons- non availability of infrastructure, conservative treatment trials, and socioeconomic reasons etc. By the time they report their condition, it is too late. Decompression, even in late reported cases, should be attempted, since this is the best chance offered, even in posttraumatic cases where there is no evidence of cord transactions. The chances of the patient recovering to an effective rehabilitation status are good [6]. 
Table 3. Postoperative and rehabilitation

\begin{tabular}{|c|c|c|c|c|c|c|}
\hline $\begin{array}{l}\text { Serial } \\
\text { no. }\end{array}$ & $\begin{array}{c}\text { Oral } \\
\text { feeding (hr) }\end{array}$ & $\begin{array}{l}\text { Postoperative } \\
\text { immobilization }\end{array}$ & $\begin{array}{l}\text { Out of bed } \\
\text { mobilization }\end{array}$ & $\begin{array}{c}\text { Early } \\
\text { complication }\end{array}$ & $\begin{array}{c}\text { Effective } \\
\text { rehabilitation }\end{array}$ & $\begin{array}{l}\text { Follow-up } \\
\qquad(\mathrm{mo})\end{array}$ \\
\hline 1 & 24 & Soft cervical collar 3 weeks & Wheel chair day 2 & Nil & Walking with aid-walker & 34 \\
\hline 2 & 24 & Soft cervical collar 3 weeks & Wheel chair day 2 & Nil & Walking with aid-walker & 33 \\
\hline 3 & 24 & Soft cervical collar 3 weeks & Wheel chair day 2 & Fever & Independent walker & 30 \\
\hline 4 & 48 & Hard collar 4 weeks & Wheel chair day 3 & Cough & Independent walker & 30 \\
\hline 5 & 24 & Soft cervical collar 3 weeks & Wheel chair day 2 & Nil & Wheel chiar mobilized & 28 \\
\hline 6 & 24 & Soft cervical collar 3 weeks & Wheel chair day 2 & Nil & Independent walker & 27 \\
\hline 7 & 24 & Soft cervical collar 3 weeks & Wheel chair day 2 & Nil & Independent walker & 27 \\
\hline 8 & 48 & Philadelphia collar 4 weeks & Wheel chair day 2 & Nil & No improvement & 26 \\
\hline 9 & 24 & - & - & $\begin{array}{l}\text { Death on } 7 \text { days due } \\
\text { to respiratory failure }\end{array}$ & - & - \\
\hline 10 & 24 & Soft cervical collar 3 weeks & Wheel chair day 2 & Nil & Independent walker & 24 \\
\hline 11 & 24 & Soft cervical collar 3 weeks & Wheel chair day 2 & Nil & Independent walker & 24 \\
\hline
\end{tabular}

The use of anterior cervical plates reduces the chances of graft loosening, extruding, or collapsing $[7,8]$. The use of titanium locking plates has effectively proven to be a better choice as no implant related complications are noted. The stability provided, increases the chance of interbody fusion. Conventional anterior cervical discectomy with fusion is thought to require postoperative neck immobilization for the promotion of bony fusion. Rigid internal fixation with anterior cervical plates may decrease graft-related complications and provide immediate stability. This stability may obviate postoperative external immobilization. However, no reports are available that address the advantages of metallic plating to obviate the use of postoperative neck immobilization and thus promote early mobilization [6,9-18].

\section{Controversy about timing of surgery}

Much controversy continues over the timing of surgery after cervical spinal cord injury [19-21]. Recent studies suggest that earlier surgical decompression within 48 hours results in improved neurologic outcome without an increase in systemic complications [2]. Aebi et al. [6] and Levi et al. [22] concluded that early surgery $(<72$ hours after spinal cord injury) was the best method of managing cervical spinal cord injury. They believed that a narrow window exists during which spinal cord injured patients could be operated on before complications develop that would postpone surgery. In addition, they speculated that early surgery may provide a better chance to reverse neurologic abnormalities than later surgery [14]. Donovan et al. [3] assessed surgical outcomes retrospectively in spinal cord injury patients and reported no difference in neurologic recovery in surgical versus nonsurgical management. The median time for surgery in their study was 13 days after spinal cord injury, with a range of 1 to 60 days. Aebi et al. [6] found that patients whose cervical dislocations were reduced early, less than 6 hours postinjury, had improved neurologic recovery over later reductions. Miller et al. [8] found that if a cervical reduction was achieved by traction within the first 8 hours of injury, greater neurologic recovery ensued compared with a similar group of age- and injury-matched control patients with cervical reductions longer than 8 hours postinjury.

\section{Late presentation-3 months following trauma or symptoms}

The sequence of pathologic changes in neural tissue is known to progress rapidly within the first 8 hours of injury $[9,23]$, and if surgery is hoped to improve neurologic function, it may be best to carry it out soon after spinal cord injury and before neuropathologic changes have been established [14]. In addition, patients with spinal cord injuries immediately after trauma are presumably in better physiologic condition than they usually are a week or so later because of the potential risk for development of morbid medical sequelae such as atelectasis, pneu- 
monia, deep vein thrombosis, and renal insufficiency. Early surgery creates the opportunity for an earlier start of the rehabilitation process, thereby decreasing overall expenses.

However, in developing countries, especially in rural areas, the patients usually do not report their condition very early. The golden standard of decompressing within 6 to 72 hour is usually not feasible for a variety of reasons-non availability of infrastructure, conservative treatment trials, socioeconomic reasons, etc. By the time they report their condition, it is too late to offer treatment. Hence, logistically early intervention is precluded by the admitting medical facilities' lack of intensive care capability and experienced personnel required to perform such surgery, necessitating the patient's transfer to a specialty referral center and thereby delaying surgery [22]. This situation is in stark contrast to that of developed countries, which is probably the reason why not many reports and studies, regarding late decompression in these type of patients are available in the literature.

\section{Our findings}

Decompression, even in late reported cases should be attempted, as that is the best chance offered for a favorable outcome, even in posttraumatic cases where there is no evidence of cord transactions. The chances of a patient recovering to effective rehabilitation status are good.

There are several weaknesses in the methodology of this study. Herbison et al. [24] found further evidence to support theories that manual muscle testing (MMT), as was used in our study and as the norm suggested by ASIA, may be inferior to measurements performed with a hand-held myometer (MYO), as was described by Scott et al. [13]. Their rationale is that for a patient to receive a grade of 3.0 by MMT, the muscle needs only a relatively small fraction of motor neurons to function properly [24]. In contrast, strength grades of greater than 3.0 require a disproportionately greater number of active motor neurons [25]. This leads to a relatively insensitive method of measuring changes in muscle strength by subjectively grouping into muscle grades. Through the use of MYO, subtle changes in muscle strength can be perceived that cannot be detected by MMT. In numerous other studies, researchers supported the use of MYO as an effective method of sensitive muscle strength testing $[7,11,26,27]$. Therefore, our data may be inaccurate because of our motor measurement method. The sample size is small, there is no control group, and randomization was not performed.

\section{Conclusions}

In late reported cervical myelopathy, anterior cervical decompression with interbody fusion is effective, improves the functional outcome in incomplete quadriplegic patients and combined with anterior cervical plating minimizes the risk of failure of grafts, and provides adequate stabilization. Decompression even in late reported cases should be attempted as it is the best chance offered for a favorable outcome, even in posttraumatic cases where there is no evidence of cord transactions. The chances of the patient recovering to effective rehabilitation status are good.

\section{Conflict of Interest}

No potential conflict of interest relevant to this article was reported.

\section{References}

1. Bohlman HH, Anderson PA. Anterior decompression and arthrodesis of the cervical spine: long-term motor improvement. Part I: Improvement in incomplete traumatic quadriparesis. J Bone Joint Surg Am 1992;74:671-82.

2. Emery SE, Bohlman HH, Bolesta MJ, Jones PK. Anterior cervical decompression and arthrodesis for the treatment of cervical spondylotic myelopathy. Two to seventeen-year follow-up. J Bone Joint Surg Am 1998;80:941-51.

3. Donovan WH, Cifu DX, Schotte DE. Neurological and skeletal outcomes in 113 patients with closed injuries to the cervical spinal cord. Paraplegia 1992;30:533-42.

4. de Oliveira JC. Anterior plate fixation of traumatic lesions of the lower cervical spine. Spine (Phila $\mathrm{Pa}$ 1976) 1987;12:324-9.

5. Gassman J, Seligson D. The anterior cervical plate. Spine (Phila Pa 1976) 1983;8:700-7.

6. Aebi M, Mohler J, Zach GA, Morscher E. Indication, surgical technique, and results of 100 surgicallytreated fractures and fracture-dislocations of the cer- 
vical spine. Clin Orthop Relat Res 1986;(203):244-57.

7. Bailey RW, Badgley CE. Stabilization of the cervical spine by anterior fusion. J Bone Joint Surg Am 1960;42:565-94.

8. Miller LS, Cotler HB, De Lucia FA, Cotler JM, Hume EL. Biomechanical analysis of cervical distraction. Spine (Phila Pa 1976) 1987;12:831-7.

9. Bohlman HH. Cervical spondylosis with moderate to severe myelopathy: a report of seventeen cases treated by Robinson anterior cervical discectomy and fusion. Spine (Phila Pa 1976) 1977;2:151-62.

10. Duan GS, Xu WL, Liu BC. Anterior decompression for the treatment of late cervical traumatic tetraplegia. Zhonghua Wai Ke Za Zhi 1984;22:757-9.

11. Graham JJ. Complications of cervical spine surgery. A five-year report on a survey of the membership of the Cervical Spine Research Society by the Morbidity and Mortality Committee. Spine (Phila Pa 1976) 1989;14:1046-50.

12. Bernhardt M, Hynes RA, Blume HW, White AA 3rd. Cervical spondylotic myelopathy. J Bone Joint Surg Am 1993;75:119-28.

13. Scott OM, Hyde SA, Goddard C, Dubowitz V. Quantitation of muscle function in children: a prospective study in Duchenne muscular dystrophy. Muscle Nerve 1982;5:291-301.

14. Ashkenazi E, Smorgick Y, Rand N, Millgram MA, Mirovsky Y, Floman Y. Anterior decompression combined with corpectomies and discectomies in the management of multilevel cervical myelopathy: a hybrid decompression and fixation technique. J Neurosurg Spine 2005;3:205-9.

15. Pascal-Moussellard H, Despeignes LR, Olindo S, Rouvillain JL, Catonne Y. Neurological recovery after cervical cord decompression for canal stenosis myelopathy. Rev Chir Orthop Reparatrice Appar Mot 2005;91:607-14.

16. Stieber JR, Brown K, Donald GD, Cohen JD. Anterior cervical decompression and fusion with plate fixation as an outpatient procedure. Spine J 2005;5:503-7.
17. Choi BW, Song KJ, Chang H. Ossification of the posterior longitudinal ligament: a review of literature. Asian Spine J 2011;5:267-76.

18. Rhee JM, Basra S. Posterior surgery for cervical myelopathy: laminectomy, laminectomy with fusion, and laminoplasty. Asian Spine J 2008;2:114-26.

19. Whitehill R, Lennox D. Late surgical reduction of cervical subluxations. Va Med 1981;108:616-7.

20. Kostuik JP, Connolly PJ, Esses SI, Suh P. Anterior cervical plate fixation with the titanium hollow screw plate system. Spine (Phila Pa 1976) 1993;18:1273-8.

21. Vaccaro AR, Daugherty RJ, Sheehan TP, et al. Neurologic outcome of early versus late surgery for cervical spinal cord injury. Spine (Phila Pa 1976) 1997;22:2609-13.

22. Levi L, Wolf A, Rigamonti D, Ragheb J, Mirvis S, Robinson WL. Anterior decompression in cervical spine trauma: does the timing of surgery affect the outcome? Neurosurgery 1991;29:216-22.

23. Adams MS, Crawford NR, Chamberlain RH, Bse, Sonntag VK, Dickman CA. Biomechanical comparison of anterior cervical plating and combined anterior/lateral mass plating. Spine J 2001;1:166-70.

24. Herbison GJ, Isaac Z, Cohen ME, Ditunno JF Jr. Strength post-spinal cord injury: myometer vs manual muscle test. Spinal Cord 1996;34:543-8.

25. Sevki K, Mehmet T, Ufuk T, Azmi H, Mercan S, Erkal B. Results of surgical treatment for degenerative cervical myelopathy: anterior cervical corpectomy and stabilization. Spine (Phila Pa 1976) 2004;29:2493500.

26. Barros Filho TE, Oliveira RP, Grave JM, Taricco MA. Corpectomy and anterior plating in cervical spine fractures with tetraplegia. Rev Paul Med 1993;111:375-7.

27. Shevelev IN, Iarikov DE, Baskov AV, Iundin VI, Kolpachkov VA, Gushcha OA. The late-period results of surgical treatment for trauma to the cervical spine and spinal cord. Zh Vopr Neirokhir Im N N Burdenko 1997;(4):19-22. 